\title{
ATRIBUTOS QUÍMICOS E BIOQUÍMICOS EM SOLOS DEGRADADOS POR MINERAÇÃO DE ESTANHO E EM FASE DE RECUPERAÇÃO EM ECOSSISTEMA AMAZÔNICO
}

\author{
Marcela Midori Yada ${ }^{(1)^{*}}$, Fábio Luiz Checchio Mingotte ${ }^{(1)}$, Wanderley José de Melo ${ }^{(2)}$, \\ Gabriel Peruca de Melo( ${ }^{(3)}$, Valéria Peruca de Melo ${ }^{(3)}$, Regina Márcia Longo ${ }^{(4)}$ e Admilson Írio \\ Ribeiro $^{(5)}$ \\ (1) Universidade Estadual Paulista, Faculdade de Ciências Agrárias e Veterinária, Programa de Pós-graduação em Agronomia/Produção \\ Vegetal, Jaboticabal, São Paulo, Brasil. \\ (2) Universidade Estadual Paulista, Faculdade de Ciências Agrárias e Veterinária, Departamento de Tecnologia, Jaboticabal, São \\ Paulo, Brasil. \\ (3) Universidade Camilo Castelo Branco, Descalvado, São Paulo, Brasil. \\ (4) Pontifícia Universidade Católica, Campinas, São Paulo, Brasil. \\ (5) Universidade Estadual Paulista, Sorocaba, São Paulo, Brasil. \\ * Autor correspondente. \\ E-mail: marcelayada@gmail.com
}

\section{RESUMO}

A mineração de cassiterita na mina Serra da Onça, localizada na Floresta Nacional do Jamari, Estado de Rondônia, causou profundas alterações físicas, químicas e biológicas nos solos. Em 1997, a área foi dividida em parcelas e foi dado início a um programa de recuperação, que consistiu na modelagem do terreno, construção de terraços, calagem, fertilização, plantio de leguminosas e plantio de espécies nativas. Em cada ano que se sucedeu, foram instaladas novas parcelas para serem recuperadas, às quais se aplicou o mesmo programa de recuperação, de tal modo que, no momento da amostragem, cada área recebeu uma nota de avaliação de 1 a 7 de acordo com o estádio visual de recuperação. Este trabalho teve por objetivo avaliar os atributos químicos e bioquímicos dos solos das diferentes áreas da mina Serra da Onça. As amostras de solo foram coletadas na camada de 0-20 cm em cada área e em áreas de mata nativa e em vegetação de capoeira localizadas no entorno. Foram avaliados: respiração basal, carbono da biomassa microbiana (CBM), quociente metabólico $\left(q \mathrm{CO}_{2}\right)$, atividade enzimática (celulase, arilsulfatase, fosfatase ácida e alcalina, desidrogenase e potencial de hidrólise do diacetato de fluoresceína - FDA), concentração de estanho total e nível de fertilidade. 
Das 12 áreas avaliadas, sete delas estão em estádio avançado de recuperação, quando comparadas com as de mata nativa e de capoeira, por meio de análise multivariada, quanto às características de respiração basal, $\mathrm{CBM}, q \mathrm{CO}_{2}$ e atividade enzimática (arilsulfatase, desidrogenase, hidrólise do FDA).

Palavras-chave: cassiterita, mineração, atividade enzimática, respiração basal, quociente metabólico, biomassa microbiana, área degradada.

\title{
ABSTRACT: CHEMICAL AND BIOCHEMICAL PROPERTIES OF SOILS DEGRADED BY TIN MINING AND IN A REHABILITATION PHASE IN THE AMAZON BASIN
}

\begin{abstract}
Tin mining in the Serra da Onça in the Jamari National Forest, State of Rondônia, Brazil, caused severe chemical, physical, and biological changes in the soil. In 1997, the area was divided into plots and a rehabilitation program was begun, which consisted of land surface modeling, construction of terraces, liming, fertilization, and planting of leguminous crops and native plants. In subsequent years, new plots were set up in the rehabilitation program so that at the time of sampling the different areas could be classified at levels from 1 to 7 according to the visual stage of rehabilitation. The objective of this study was to evaluate the chemical and biochemical properties of the soils of different areas around the Serra da Onça mine. Soil samples were taken from the $0-20 \mathrm{~cm}$ depth in each of the different plots and in native forest and coppice areas around the Serra da Onça mine. Basal respiration, microbial biomass carbon (MBC), metabolic quotient $\left(\mathrm{qCO}_{2}\right.$ ), enzyme activity (cellulase, arylsulphatase, acid and alkaline phosphatase, dehydrogenase, and potential for hydrolysis of fluorescein diacetate [FDA]), total tin concentration, and soil fertility were evaluated in soil samples. Of the 12 areas evaluated through multivariate analysis in regard to soil basal respiration, $\mathrm{MBC}, q \mathrm{CO}_{2}$, and enzyme activity (arylsulphatase, dehydrogenase, and FDA hydrolysis), seven of them are in an advanced stage of rehabilitation in comparison with areas of undisturbed forest and secondary forest.
\end{abstract}

Keywords: tin mining, soil enzyme activity, basal respiration, metabolic quocient, microbial biomass carbon, degraded area.

\section{INTRODUÇÃO}

A região amazônica destaca-se por sua riqueza em recursos naturais, exibindo grande biodiversidade e riqueza mineral. A floresta tropical é fechada, formada em boa parte por árvores de grande porte, estabelecida em solo com fina camada rica em nutrientes, originados da decomposição de folhas, frutos, ramos e animais mortos. Apesar da fragilidade do solo, o ecossistema equilibrado e as temperaturas elevadas, combinados com elevado índice pluviométrico, permitem bom desenvolvimento da fauna e flora (Margulis, 2003).

A extração de recursos minerais é prática que traz sérias consequências para o ambiente pelo efeito degradativo, reduzindo a vegetação nativa e a fauna e removendo ou alterando a camada fértil do solo (Mendes Filho, 2004). A vegetação e a fauna nativa são destruídas ou excluídas, a camada fértil do solo é retirada ou perdida e a qualidade e o regime de vazão do sistema hídrico são modificados, transformando-se em área degradada, segundo Ibama (1990).

As transformações dos materiais orgânicos são mediadas pela atividade microbiana do solo, que desempenha papel essencial na manutenção ou na reabilitação de solos degradados (Srisvastava e Singh, 1991), de tal forma que os indicadores microbiológicos refletem as condições de manejo e são úteis para determinar os seus efeitos na qualidade do solo e na sustentabilidade das práticas agrícolas (Lorenz et al., 1992).

As atividades envolvidas na mineração de cassiterita dão origem a substratos com características que decorrem, principalmente, do tipo e da composição da rocha matriz, dos processos de mineração, da forma e do tempo de exposição do material remanescente. Geralmente são substratos muito pobres em nutrientes e desprovidos de matéria orgânica, o que dificulta o estabelecimento e desenvolvimento da vegetação.

Um componente importante na exploração de recursos minerais é a recuperação das áreas degradadas geradas no processo de mineração, principalmente na mineração de superfície, que apresenta grandes impactos sobre o solo e a paisagem. Essa recuperação é uma tarefa complexa, pois envolve técnicas e estratégias dependentes do uso futuro da área (Sánchez, 2000). Assim, as atividades de exploração mineral devem ser cuidadosamente planejadas e a recuperação das áreas degradadas, considerando o uso final do solo, 
deve fazer parte do plano de exploração, e as práticas de conservação do solo devem ser aplicadas desde o início, preservando o potencial produtivo do solo (Ribeiro, 2000).

Uma vez iniciado um processo de recuperação, há necessidade de avaliações para acompanhar as etapas de melhoria. A biomassa microbiana, que representa a parte viva da matéria orgânica do solo, é considerada um indicador rápido do estado e da mudança das propriedades edáficas (Williamson e Johnson, 1994).

As transformações mediadas pela biomassa microbiana são catalisadas por enzimas, de modo que a quantificação da atividade de enzimas do solo indica alterações nos processos metabólicos (Dick et al., 1996) e, aliada aos atributos biológicos, fornece indicativo do estádio de recuperação de áreas degradadas.

A multiplicidade de fatores químicos, físicos e biológicos que controlam os processos bioquímicos no solo e suas variações no tempo e no espaço, aliada à complexidade do sistema solo, dificulta a capacidade de definir a qualidade e identificar variáveis indicadoras do funcionamento eficiente do solo, de tal forma que um conjunto de indicadores, englobando atributos físicos, químicos e biológicos, deve ser utilizado nas análises de qualidade do solo (Doran e Parkin, 1994).

Este trabalho teve por objetivo avaliar atributos químicos e bioquímicos em solos degradados pela mineração de cassiterita na mina Serra da Onça, Floresta Nacional do Jamari, Estado de Rondônia, que se encontram em diferentes estádios de recuperação.

\section{MATERIAL E MÉTODOS}

\section{Histórico da área}

A Floresta Nacional do Jamari (Flona do Jamari) tem 215.000 ha, dos quais $90 \%$ estão cobertos por floresta tropical aberta, localizada nas coordenadas geográficas $09^{\circ} 00^{\prime} 00^{\prime \prime}$ e $09^{\circ} 30^{\prime} 00^{\prime \prime}$ latitude sul e $62^{\circ} 44^{\prime} 05^{\prime}$ e e $63^{\circ} 16^{\prime} 54^{\prime \prime}$ longitude oeste, município de Itapuã d'Oeste, Estado de Rondônia, Brasil.

O clima da região é tropical chuvoso (Aw), segundo Köppen, e se caracteriza por ter um período seco durante a estação de inverno, quando ocorre déficit hídrico moderado. As médias anuais são: precipitação pluvial entre 2.200 e $2.600 \mathrm{~mm}$; temperatura do ar entre 24 e $26{ }^{\circ} \mathrm{C}$; umidade relativa do ar entre 80 e $90 \%$, no verão, e $75 \%$, no outono e inverno, havendo uma estação seca bem definida, com período mais crítico de julho a agosto. A evapotranspiração potencial (ETP) é alta durante todo o ano, apresentando médias mensais superiores a $100 \mathrm{~mm}$ (Ibama, 2005).
$\mathrm{Na}$ área em estudo, predominam os solos Latossolo Vermelho-Amarelo distroférrico e Latossolo Amarelo distroférrico (Embrapa, 1999).

O programa de recuperação das áreas de mineração de cassiterita na Floresta Nacional do Jamari objetiva reintegrar as áreas mineradas à paisagem dominante da região. Foi iniciado em 1990, com a assinatura de um Termo de Compromisso de Ajustamento de Conduta com o IBAMA, com o objetivo de disciplinar a realização das medidas necessárias à correção dos danos causados ao meio ambiente pela mineração de cassiterita. Em 1997, a área foi dividida em parcelas e foram iniciadas ações de recuperação, que consistiram na modelagem do terreno, construção de terraços, calagem, adubação mineral e orgânica, cultivo de leguminosas e plantio de espécies nativas.

A área em estudo situa-se na antiga mina denominada Serra da Onça, localizada dentro da Floresta Nacional do Jamari.

\section{Descrição dos tratamentos}

As áreas degradadas eram constituídas por piso de lavra, rejeito seco, rejeito capeado e rejeito úmido. O piso de lavra é o fundo da cava, resultante da exploração do minério. O rejeito seco é composto principalmente pela fração areia segmentada próximo à barragem de contenção de rejeitos após a extração do minério. O rejeito capeado é um substrato heterogêneo, formado pelo rejeito seco com cobertura de material fértil de outras áreas ainda não mineradas. O rejeito úmido é caracterizado por áreas com sedimentos com granulometria variável, sujeitas à inundação.

Além dos diferentes substratos, as áreas estudadas apresentam diferentes épocas de início de plantio de quatro espécies de leguminosas (1999/2000, 2001/2002, 2002/2003 e 2005/2006). As leguminosas utilizadas foram Crotalaria juncea (crotalária), Canavalia ensiformis (feijão-de-porco), Cajanus cajam (feijão-guandu) e Mucuna aterrima (mucuna-preta). Antes da semeadura das leguminosas, foi realizada escarificação com aplicação de $2 \mathrm{Mg} \mathrm{ha}{ }^{-1}$ de calcário e posterior gradeação. Seguiu-se adubação com $45 \mathrm{~kg} \mathrm{ha}^{-1}$ de $\mathrm{N}, 45 \mathrm{~kg} \mathrm{ha}^{-1}$ de $\mathrm{P}_{2} \mathrm{O}_{5}$ e $45 \mathrm{~kg} \mathrm{ha}^{-1}$ de $\mathrm{K}_{2} \mathrm{O}$, aplicados a lanço, na forma de ureia $(45 \% \mathrm{~N})$, superfosfato simples $\left(18 \% \mathrm{P}_{2} \mathrm{O}_{5}\right)$ e cloreto de potássio $\left(60 \% \mathrm{~K}_{2} \mathrm{O}\right)$.

No momento do florescimento das leguminosas, a massa verde foi incorporada superficialmente por meio de gradagem.

As áreas foram classificadas em níveis de 1 a 7 , de acordo com as atividades realizadas nas mesmas, de acordo com o plano de recuperação de áreas degradadas, que consistiu desde a modelagem do terreno, construção de terraços, calagem, fertilização, plantio de leguminosas, plantio de espécies nativas, enriquecimento até o monitoramento (Quadro 1). 
Os níveis variam de 1 a 7 , sendo que o nível 1 , que indica início das ações de recuperação, até o nível 7, após realizadas todas as atividades de recuperação. Os tratamentos estudados foram em número de 12 , distribuídos em delineamento experimental inteiramente casualizado com três repetições. Os códigos atribuídos aos tratamentos considerando o substrato e o nível de ação de recuperação em cada área encontram-se no quadro 2.

Os solos para as análises enzimáticas foram coletados em janeiro de 2010 e as amostragens para as análises químicas e microbiológicas foram realizadas em janeiro de 2011. As coletas foram realizadas na camada de $0-20 \mathrm{~cm}$. Em cada parcela, foram obtidas quatro amostras simples, sendo duas na projeção da copa e duas entre plantas, que foram misturadas e homogeneizadas para formar uma amostra representativa da parcela. As amostras foram peneiradas em malha de $5 \mathrm{~mm}$ de abertura, acondicionadas em sacos plásticos e mantidas em refrigeração $\left(4^{\circ} \mathrm{C}\right)$ conforme procedimento descrito por Forster (1995).

Quadro 1. Ações aplicadas de acordo com os níveis de recuperação em área degradada pela mineração de cassiterita na Floresta Nacional do Jamari, RO

\begin{tabular}{|c|c|c|c|c|c|c|c|}
\hline \multirow[t]{2}{*}{$\begin{array}{l}\text { Nivel de } \\
\text { recuperação }^{(1)}\end{array}$} & \multicolumn{7}{|c|}{ Ação aplicada } \\
\hline & $\begin{array}{l}\text { Recomposição } \\
\text { topográfica; } \\
\text { Preparo superficial; } \\
\text { Calagem; } \\
\text { Adubação química; } \\
\text { Adubação verde } \\
\text { (um ano) }\end{array}$ & $\begin{array}{l}\text { Preparo } \\
\text { superficial; } \\
\text { Adubação } \\
\text { química; } \\
\text { Adubação verde } \\
\text { (dois anos) }\end{array}$ & $\begin{array}{l}\text { Preparo } \\
\text { superficial; } \\
\text { Adubação } \\
\text { química; } \\
\text { Adubação } \\
\text { verde } \\
\text { (três anos) }\end{array}$ & $\begin{array}{l}\text { Plantio de } \\
\text { mudas; } \\
\text { Adubação } \\
\text { química; } \\
\text { Adubação } \\
\text { orgânica }\end{array}$ & $\begin{array}{l}\text { Adubação } \\
\text { química; } \\
\text { Manutenção } \\
\text { das mudas; } \\
\text { Replantio de } \\
\text { mudas }\end{array}$ & $\begin{array}{l}\text { Adubação } \\
\text { química; } \\
\text { Manutenção } \\
\text { das mudas; } \\
\text { Replantio } \\
\text { de mudas; } \\
\text { Enriquecimento }\end{array}$ & $\begin{array}{l}\text { Enriquecimento } \\
\text { Monitoramento }\end{array}$ \\
\hline 1 & & & & & & & \\
\hline 2 & & & & & & & \\
\hline 3 & & & & & & & \\
\hline 4 & & & & & & & \\
\hline 5 & & & & & & & \\
\hline 6 & & & & & & & \\
\hline 7 & & & & & & & \\
\hline
\end{tabular}

Quadro 2. Códigos de descrição dos tratamentos de acordo com o substrato, data de início do plantio das leguminosas e nível de recuperação das áreas degradadas por mineração de cassiterita na Floresta Nacional do Jamari, RO, submetidas aos processos de recuperação, além das áreas de mata nativa e de capoeira

\begin{tabular}{|c|c|c|c|}
\hline Substrato & Plantio das leguminosas & Nível de recuperação(1) & Tratamento \\
\hline Piso de Lavra & $2001 / 2002$ & 4 & PL1N4 \\
\hline Piso de Lavra & $2001 / 2002$ & 6 & PL2N6 \\
\hline Piso de Lavra & $2002 / 2003$ & 5 & PL3N5 \\
\hline Rejeito Seco & $2005 / 2006$ & 5 & RS4N5 \\
\hline Rejeito Seco & $2005 / 2006$ & 5 & RS5N5 \\
\hline Rejeito Capeado & $2005 / 2006$ & $5 / 6$ & $\mathrm{RC} 6 \mathrm{~N} 5 / 6$ \\
\hline Piso de Lavra & $2005 / 2006$ & 6 & PL7N6 \\
\hline Piso de Lavra & $2005 / 2006$ & 6 & PL8N6 \\
\hline Rejeito Úmido & $2005 / 2006$ & 4 & RU9N4 \\
\hline Piso de Lavra & $1999 / 2000$ & 6 & PL10N6 \\
\hline Mata & & & MATA \\
\hline Capoeira & & & CAP \\
\hline
\end{tabular}




\section{Atributos químicos e bioquímicos avaliados}

A caracterização química foi realizada nas amostras secas ao ar e passadas em peneira com $2 \mathrm{~mm}$ de abertura de malha, segundo método descrito em Raij et al. (2001).

A atividade da celulase foi determinada pelo método proposto por Pancholy e Rice (1973). O solo foi incubado a $30{ }^{\circ} \mathrm{C}$ na presença e na ausência do substrato carboximetilcelulose por $24 \mathrm{~h}$. Após o período de incubação, determinou-se o equivalente de glicose por espectrofotômetro de cor.

A determinação da atividade da desidrogenase foi feita pelo método descrito em Melo et al. (2010). As amostras de solo foram incubadas na presença e na ausência do substrato cloreto de trifeniltetrazólio (TTC) a $30^{\circ} \mathrm{C}$ por $24 \mathrm{~h}$, seguindo-se a quantificação do trifenilformazan (TPF) por espectrofotômetro de cor.

Para determinar a atividade das enzimas fosfatase ácida e alcalina, as amostras de solo foram incubadas na presença e na ausência do substrato $p$-nitrofenilfosfato de sódio em solução-tampão pH 6,5 e pH 11, respectivamente, a $37^{\circ} \mathrm{C}$ por $30 \mathrm{~min}$. Em seguida, determinou-se a quantidade de $p$-nitrofenol liberada no extrato por espectrofotometria de cor (Eivazi e Tabatabai, 1977).

A atividade de arilsulfatase foi determinada como método proposto por Tabatabai e Bremner (1970). Após o período de incubação por $1 \mathrm{~h}$ a $37^{\circ} \mathrm{C}$, na presença e na ausência de $p$-nitrofenilsulfato de potássio em solução-tampão acetato $\mathrm{pH} 5,8$, quantificou-se o teor de $p$-nitrofenol liberado por espectrofotômetro de cor.

$\mathrm{Na}$ determinação do potencial de hidrólise do diacetato de fluoresceína (FDA), amostras de solo foram incubadas com e sem o substrato FDA em meio tamponado com solução-tampão fosfato de sódio $60 \mathrm{mmol} \mathrm{L}-1, \mathrm{pH} 7,6$, por $3 \mathrm{~h}$ a $24^{\circ} \mathrm{C}$, sob agitação. Em seguida, a fluoresceína formada foi extraída e determinada por espectrofotômetro de cor (Schuner e Rosswall, 1982).

A respiração basal do solo foi determinada pelo método descrito em Alef e Nannipieri (1995), quantificando $\mathrm{o}^{\mathrm{CO}_{2}}$ liberado durante três dias de incubação a $25{ }^{\circ} \mathrm{C}$, capturado em solução de $\mathrm{NaOH} 0,05 \mathrm{~mol} \mathrm{~L}^{-1}$ e dosado por titulação com solução padronizada de $\mathrm{HCl} 0,05 \mathrm{~mol} \mathrm{~L}^{-1}$.

O carbono da biomassa microbiana (CBM) foi avaliado, empregando-se o método proposto por Vance et al. (1987). As amostras de solo, em duplicata, uma fumigada e outra não fumigada, foram incubadas em dessecador por $24 \mathrm{~h}$, com clorofórmio ou água, respectivamente. Após a extração do $\mathrm{C}$, seguiu-se a sua quantificação pela oxidação por via úmida.

Com os valores da respiração basal e do CBM, calculou-se o quociente metabólico $\left(q \mathrm{CO}_{2}\right)$ com base em Anderson e Domsch (1993).

\section{Análise dos resultados}

Os resultados foram submetidos à análise da variância e, nos casos em que o teste $F$ foi significativo, as médias foram comparadas pelo teste de Scott-Knott a $5 \%$.

Em complemento, a estrutura multivariada contida nos dados foi explorada pelas técnicas de agrupamento pelo método hierárquico, processada com a distância euclidiana e o método Ward; componentes principais, processada com a matriz de covariância e análise de escalonamento, processada com a matriz de distância construída com a distância euclidiana (Hair et al., 2005).

\section{RESULTADOS E DISCUSSÃO}

Os resultados para os atributos químicos do solo (Quadro 3) foram comparados com os níveis de fertilidade adotados por Raij et al. (1997). Os valores de $\mathrm{pH}\left(\mathrm{CaCl}_{2}\right)$ variaram de 3,83 a 5,37; e os solos de mata nativa (MATA), capoeira (CAP), RS4N5 e PL10N6 apresentaram maior acidez. Desempenhos semelhantes foram observados para a saturação por bases (V), em que os solos de MATA, CAP e PL10N6 apresentaram os menores valores, o que se deve aos baixos teores de $\mathrm{Ca}^{2+}$ e elevada acidez potencial. Na região amazônica, a toxidez por $\mathrm{Al}^{3+}$ é frequente (Smyth, 1996). Em solos de floresta em Rondônia, observou-se maior acidez, quando comparados a solos sob pastagem nas mesmas condições (Longo, 1999). Os teores mais elevados de $\mathrm{Ca}^{2+}$ $\mathrm{e} \mathrm{Mg}^{2+}$ nos solos degradados em fase de recuperação se devem à calagem.

$\mathrm{O}$ tratamento MATA apresentou o maior teor de matéria orgânica $\left(25,67 \mathrm{mg} \mathrm{dm}^{-3}\right)$, seguido pelo CAP $\left(18,00 \mathrm{mg} \mathrm{dm}^{-3}\right)$ e pelos demais tratamentos, que não diferiram entre si. $\mathrm{O}$ baixo teor de $\mathrm{MO}$ na área degradada está relacionado ao processo de mineração, que envolve a remoção da cobertura vegetação original, lavagem e separação do material coletado. Isso significa que os tratamentos até então aplicados não conseguiram repor a MO perdida.

A CTC, que está diretamente relacionada ao teor de MO, também foi maior nos tratamentos MATA $\left(86,31 \mathrm{mmol}_{\mathrm{c}} \mathrm{dm}^{-3}\right)$ e CAP $\left(66,67 \mathrm{mmol}_{\mathrm{c}} \mathrm{dm}^{-3}\right)$, que diferiram entre si e dos solos em recuperação. Considerando a MO e a CTC como critérios de qualidade, concluiu-se que os solos degradados ainda não podem ser considerados como recuperados, apesar da vegetação estabelecida, e que todos os solos em recuperação encontram-se em um mesmo estádio.

Os teores de $\mathrm{P}$ extraído pelo método da resina de troca iônica são considerados médios (Raij et al., 1997) e foram maiores no tratamento MATA $\left(8,67 \mathrm{mg} \mathrm{dm}^{-3}\right)$. Adotando o P-resina como índice de qualidade, os solos degradados em recuperação já teriam atingido o nível da capoeira. 


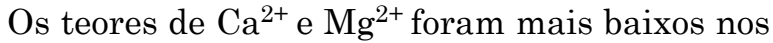
tratamentos MATA e CAP, o que se deve à calagem aplicada no processo de recuperação. Algumas áreas em recuperação não diferiram dos tratamentos MATA e CAP, o que pode ser atribuído a uma lavagem desses cátions. Os teores de $\mathrm{K}^{+}$variaram de 0,50 a $0,97 \mathrm{mmol}_{\mathrm{c}} \mathrm{dm}^{-3}$ e não foram observadas diferenças entre os solos estudados, o que pode estar relacionado com a suplementação anual de $10 \mathrm{~kg} \mathrm{ha}^{-1}$ de $\mathrm{K}_{2} \mathrm{O}$. Segundo Longo et al. (2005), as diferenças na fertilidade entre solos das áreas degradadas sob recuperação se devem aos tipos de cobertura vegetal implantados, às características do solo/substrato em cada área e à calagem e adubação de cobertura aplicados anualmente no solo.

Considerando a respiração basal, que expressa a atividade metabólica da fração viva da biomassa microbiana do solo, o maior valor foi observado no tratamento CAP (2,59 $\mathrm{\mu g} \mathrm{kg}^{-1} \mathrm{~h}^{-1} \mathrm{CO}_{2}$, base seca), que diferiu dos demais (Quadro 4). A respiração microbiana é um bom indicador microbiológico em solos de áreas degradadas e em sistemas florestais (Peña et al., 2005).

O carbono da biomassa microbiana do solo (CBM) variou de 55,14 (RS5N5) a 301,34 $\mathrm{mg} \mathrm{kg}^{-1} \mathrm{C}$ (base seca) (CAP) (Quadro 4). Os solos dos tratamentos MATA, CAP, PL1N4, PL3N5, RS4N5, PL8N6, PL10N6 apresentaram teores de CBM superiores aos solos das demais áreas e não diferiram entre si. Os teores de CBM observados são semelhantes aos encontrados em ecossistemas florestais brasileiros, sob condições edafoclimáticas diversas, por outros autores (D'Andréa et al., 2002; Barreta et al., 2005). As condições distintas do solo sob vegetação nativa, juntamente com a ausência de perturbações decorrentes de atividade antrópica, tornam possível a existência de altos teores de CBM (D’Andréa et al., 2002).

É importante observar, contudo, que uma elevada respiração basal pode sugerir a presença de agentes estressantes, motivo pelo qual é sempre importante considerar a respiração basal em relação à $\mathrm{BMS}$, que é o quociente metabólico $\left(q \mathrm{CO}_{2}\right)$. Observou-se que não houve diferença entre os tratamentos, variando de 0,008 a $0,014 \mathrm{mg} \mathrm{mg}^{-1} \mathrm{C} \mathrm{h}^{-1} \mathrm{CO}_{2}$. Em matas sob diferentes ecossistemas, os valores de quociente metabólico têm variado de 0,04 a $0,10 \mathrm{mg} \mathrm{mg}^{-1} \mathrm{C} \mathrm{h}^{-1} \mathrm{CO}_{2}$ (Carvalho, 2005). Baixos valores para $q \mathrm{CO}_{2}$ são atribuídos a áreas que estão num estádio avançado de equilibro, onde o acúmulo de energia é maior (Anderson e Domsch, 1990).

As enzimas que catalisam a hidrólise do FDA representam o potencial heterotrófico da biota do solo, pois incluem enzimas que atuam em processos de biodegradação de substâncias orgânicas como proteases, lipases e esterases (Dick et al., 1996).

O potencial de hidrólise do FDA foi maior no tratamento MATA $\left(162,78 \mathrm{mg} \mathrm{kg}^{-1} \mathrm{~h}^{-1} \mathrm{de}\right.$ fluoresceína, base seca) (Quadro 4). Carneiro et al. (2008) observaram que a hidrólise do FDA aumentou rapidamente após a reabilitação de uma área minerada para extração de bauxita, com valores similares nos tratamentos campo, serra e áreas em reabilitação após um ano, resultados que não corroboram os verificados neste trabalho, uma vez que tratamentos com 10 anos em recuperação ainda não atingiram o nível de atividade da mata nativa. Esse fato pode ser atribuído ao grau de degradação causado pelo sistema de mineração adotado.

Quadro 3. Atributos químicos nas amostras de solo de áreas degradadas por mineração de cassiterita na Floresta Nacional do Jamari, RO, submetidas a processos de recuperação, e de áreas de mata nativa e de capoeira

\begin{tabular}{lrrrrrrrrrr}
\hline Tratamento & $\mathbf{P}$ & $\mathbf{M O}$ & $\mathbf{p H}\left(\mathbf{C a C l}_{\mathbf{2}}\right)$ & $\mathbf{K}^{+}$ & $\mathbf{C a}^{2+}$ & $\mathbf{M g}^{2+}$ & $\mathbf{H}+\mathbf{A l}$ & $\mathbf{S B}$ & $\mathbf{C T C}$ & $\mathbf{V}$ \\
\hline & $\mathrm{mg} \mathrm{dm}$ & $\mathrm{g} \mathrm{dm}{ }^{-3}$ & & & & $\mathrm{mmol}_{\mathrm{c}} \mathrm{dm}^{-3}$ & & \\
PL1N4 & $2,67 \mathrm{~b}$ & $11,67 \mathrm{c}$ & $4,57 \mathrm{a}$ & $0,67 \mathrm{a}$ & $3,00 \mathrm{~b}$ & $2,67 \mathrm{a}$ & $25,67 \mathrm{c}$ & $6,33 \mathrm{~b}$ & $32,00 \mathrm{c}$ & $21,00 \mathrm{a}$ \\
PL2N6 & $2,33 \mathrm{~b}$ & $10,67 \mathrm{c}$ & $5,00 \mathrm{a}$ & $0,57 \mathrm{a}$ & $5,67 \mathrm{a}$ & $4,00 \mathrm{a}$ & $15,33 \mathrm{c}$ & $10,33 \mathrm{a}$ & $25,67 \mathrm{c}$ & $38,00 \mathrm{a}$ \\
PL3N5 & $1,67 \mathrm{~b}$ & $12,33 \mathrm{c}$ & $4,97 \mathrm{a}$ & $0,80 \mathrm{a}$ & $6,00 \mathrm{a}$ & $3,67 \mathrm{a}$ & $18,67 \mathrm{c}$ & $10,67 \mathrm{a}$ & $29,33 \mathrm{c}$ & $35,67 \mathrm{a}$ \\
RS4N5 & $1,67 \mathrm{~b}$ & $9,33 \mathrm{c}$ & $4,30 \mathrm{~b}$ & $0,73 \mathrm{a}$ & $2,67 \mathrm{~b}$ & $1,67 \mathrm{a}$ & $20,33 \mathrm{c}$ & $5,33 \mathrm{~b}$ & $25,67 \mathrm{c}$ & $20,67 \mathrm{a}$ \\
RS5N5 & $3,00 \mathrm{~b}$ & $6,33 \mathrm{c}$ & $4,80 \mathrm{a}$ & $0,53 \mathrm{a}$ & $2,67 \mathrm{~b}$ & $2,00 \mathrm{~b}$ & $13,67 \mathrm{~b}$ & $5,00 \mathrm{~b}$ & $18,67 \mathrm{c}$ & $25,33 \mathrm{a}$ \\
RC6N5/6 & $2,33 \mathrm{~b}$ & $9,67 \mathrm{c}$ & $5,37 \mathrm{a}$ & $0,50 \mathrm{a}$ & $5,33 \mathrm{a}$ & $4,67 \mathrm{a}$ & $16,33 \mathrm{c}$ & $10,67 \mathrm{a}$ & $27,00 \mathrm{c}$ & $39,33 \mathrm{a}$ \\
PL7N6 & $2,33 \mathrm{~b}$ & $11,33 \mathrm{c}$ & $4,87 \mathrm{a}$ & $0,63 \mathrm{a}$ & $4,33 \mathrm{a}$ & $3,67 \mathrm{a}$ & $24,67 \mathrm{c}$ & $8,67 \mathrm{a}$ & $33,33 \mathrm{c}$ & $28,67 \mathrm{a}$ \\
PL8N6 & $2,33 \mathrm{~b}$ & $11,67 \mathrm{c}$ & $4,90 \mathrm{a}$ & $0,73 \mathrm{a}$ & $5,67 \mathrm{a}$ & $3,33 \mathrm{a}$ & $18,67 \mathrm{c}$ & $10,00 \mathrm{a}$ & $28,67 \mathrm{c}$ & $31,67 \mathrm{a}$ \\
RU9N4 & $2,33 \mathrm{~b}$ & $6,67 \mathrm{c}$ & $4,77 \mathrm{a}$ & $0,60 \mathrm{a}$ & $2,33 \mathrm{~b}$ & $1,67 \mathrm{~b}$ & $13,67 \mathrm{c}$ & $5,00 \mathrm{~b}$ & $18,67 \mathrm{c}$ & $25,00 \mathrm{a}$ \\
PL10N6 & $2,00 \mathrm{~b}$ & $5,67 \mathrm{c}$ & $4,43 \mathrm{~b}$ & $0,63 \mathrm{a}$ & $1,67 \mathrm{~b}$ & $1,00 \mathrm{~b}$ & $20,33 \mathrm{c}$ & $3,67 \mathrm{~b}$ & $24,00 \mathrm{c}$ & $14,00 \mathrm{~b}$ \\
Mata & $8,67 \mathrm{a}$ & $25,67 \mathrm{a}$ & $3,83 \mathrm{~b}$ & $0,97 \mathrm{a}$ & $1,00 \mathrm{~b}$ & $1,00 \mathrm{~b}$ & $83,33 \mathrm{a}$ & $3,00 \mathrm{~b}$ & $86,33 \mathrm{a}$ & $3,67 \mathrm{~b}$ \\
Capoeira & $2,33 \mathrm{~b}$ & $18,00 \mathrm{~b}$ & $3,97 \mathrm{~b}$ & $0,53 \mathrm{a}$ & $1,33 \mathrm{~b}$ & $1,00 \mathrm{~b}$ & $63,67 \mathrm{~b}$ & $3,00 \mathrm{~b}$ & $66,67 \mathrm{~b}$ & $4,33 \mathrm{~b}$ \\
\hline
\end{tabular}

$\mathrm{P}, \mathrm{K}^{+}, \mathrm{Ca}^{2+}, \mathrm{Mg}^{2+}$ : extraídos pelo método da resina de troca iônica mista; MO: matéria orgânica, por oxidação com solução de dicromato de potássio, método colorimétrico; $\mathrm{H}+\mathrm{Al}$ : acidez potencial pelo método tampão SMP; SB: soma de bases; CTC: capacidade de troca catiônica; V: saturação por bases. Médias, na mesma coluna, seguidas pela mesma letra não diferem entre si pelo teste Scott-Knott a $5 \%$. 


\begin{tabular}{|c|c|c|c|c|c|}
\hline Tratamento & CBM & Respiração basal & $q \mathrm{CO}_{2}$ & Desidrogenase & Hidrólise do FDA \\
\hline & $\mathrm{mg} \mathrm{kg}^{-1} \mathrm{C}$ & $\mathrm{mg} \mathrm{kg}{ }^{-1} \mathrm{~h}^{-1} \mathrm{CO}_{2}$ & $\mathrm{mg} \mathrm{mg}{ }^{-1} \mathrm{C} \mathrm{h}^{-1} \mathrm{CO}_{2}$ & $\mathrm{mg} \mathrm{kg}^{-1} \mathrm{~h}^{-1} \mathrm{TPF}^{(1)}$ & $\mathrm{mg} \mathrm{kg}^{-1} \mathrm{~h}^{-1}$ fluoresceína \\
\hline PL1N4 & $275,08 \mathrm{a}$ & $1,97 \mathrm{c}$ & $0,008 \mathrm{a}$ & $0,41 \mathrm{c}$ & $86,22 \mathrm{c}$ \\
\hline PL2N6 & $125,01 \mathrm{~b}$ & $1,37 \mathrm{~d}$ & $0,013 \mathrm{a}$ & $0,26 \mathrm{c}$ & $38,40 \mathrm{c}$ \\
\hline PL3N5 & $218,03 \mathrm{a}$ & $2,21 \mathrm{~b}$ & $0,011 \mathrm{a}$ & $0,75 \mathrm{~b}$ & $53,46 \mathrm{c}$ \\
\hline RS4N5 & $266,38 \mathrm{a}$ & $1,89 \mathrm{c}$ & $0,008 \mathrm{a}$ & $0,24 \mathrm{c}$ & $56,71 \mathrm{c}$ \\
\hline RS5N5 & $55,14 \mathrm{~b}$ & $0,75 \mathrm{e}$ & $0,014 \mathrm{a}$ & $0,27 \mathrm{c}$ & $49,01 \mathrm{c}$ \\
\hline RC6N5/6 & $168,75 \mathrm{~b}$ & $1,85 \mathrm{c}$ & $0,011 \mathrm{a}$ & $0,57 \mathrm{~b}$ & $40,70 \mathrm{c}$ \\
\hline PL7N6 & $166,59 \mathrm{~b}$ & $1,49 \mathrm{~d}$ & $0,009 \mathrm{a}$ & $0,29 \mathrm{c}$ & $77,10 \mathrm{c}$ \\
\hline PL8N6 & 208,96 a & $1,70 \mathrm{c}$ & $0,008 \mathrm{a}$ & $1,48 \mathrm{a}$ & $54,32 \mathrm{c}$ \\
\hline RU9N4 & $104,40 \mathrm{~b}$ & $1,41 \mathrm{~d}$ & $0,014 \mathrm{a}$ & $0,22 \mathrm{c}$ & $45,35 \mathrm{c}$ \\
\hline PL10N6 & $201,02 \mathrm{a}$ & $1,77 \mathrm{c}$ & $0,009 \mathrm{a}$ & $0,30 \mathrm{c}$ & $70,73 \mathrm{c}$ \\
\hline Mata & $207,80 \mathrm{a}$ & $2,08 \mathrm{c}$ & $0,010 \mathrm{a}$ & $1,30 \mathrm{a}$ & $162,78 \mathrm{a}$ \\
\hline Capoeira & $301,34 \mathrm{a}$ & $2,59 \mathrm{a}$ & $0,009 \mathrm{a}$ & $0,74 \mathrm{~b}$ & $105,77 \mathrm{~b}$ \\
\hline
\end{tabular}

(1) TPF: trifenilformazan. Médias seguidas pela mesma letra na mesma coluna não diferem entre si pelo teste Scott-Knott a $5 \%$.

Atividade microbiana deve ser maior em solos sob vegetação natural do que em outros tipos de vegetação ou culturas, pois a microbiota é favorecida pela cobertura vegetal, pelo acúmulo de material orgânico e pela fonte de nutrientes para o desenvolvimento microbiano (Cardoso e Freitas, 1992; Moreira e Siqueira, 2002).

A atividade de desidrogenase foi mais elevada nos tratamentos MATA e PL8N6 (Quadro 4). A atividade da desidrogenase reflete a atividade oxidativa total da microbiota do solo e pode ser bom indicador da atividade microbiana, sendo estimulada pela adição de material orgânico ao solo (Garcia et al., 1997). Foi sensível para medir alterações provocadas pela atividade da mineração nessa mesma área de estudo, permitindo detectar atividade mesmo no solo degradado sem tratamento (Teixeira, 2004). Essa área estava sendo submetida ao plano de recuperação há seis anos e seu nível de recuperação era considerado nível 6. Outras áreas de piso de lavra com mais tempo em recuperação apresentavam atividade de desidrogenase menor, o que se justifica pela estrutura física e composição química do resíduo, que permitiu rápido desenvolvimento da cobertura vegetal.

A fosfatase ácida variou de 33,68 a $73,39 \mathrm{mg} \mathrm{kg}^{-1} \mathrm{~h}^{-1}$ de $p$-nitrofenol e não foi influenciada pelos tratamentos, não obstante os teores de P-resina fossem mais baixos nas áreas mineradas do que na mata nativa (Quadro 5). Segundo Raij et al. (1997), o teor de P-resina nas áreas degradadas em recuperação $\left(1,67-3,00 \mathrm{mg} \mathrm{dm}^{-3}\right)$ é considerado muito baixo a baixo, enquanto o da mata nativa é alto. As fosfatases (ácida e alcalina) têm sido muito estudadas em razão da sua alta atividade nos solos e sua importância na mineralização do $\mathrm{P}$ e na nutrição das plantas (Tabatabai, 1994; Dick, 1997). Entretanto, no contexto da área em estudo, a síntese dessa não foi estimulada pela deficiência nos demais nutrientes, principalmente o $\mathrm{C}$, fonte de energia para o crescimento microbiano.

A arilsulfatase está envolvida no metabolismo do Se catalisa a hidrólise de ésteres de sulfato, uma das formas orgânicas do S, sendo responsável pela mineralização da forma orgânica, liberando sulfato, que é a forma em que o S é assimilado pelas plantas (Schinner et al., 1996). A atividade arilsulfatase foi maior nos tratamentos MATA, CAP e PL10N6 (Quadro 5), de modo que, em relação a essa enzima, o tratamento PL10N6 já atingiu as condições da mata nativa.

Em relação à atividade da celulase, não se detectou diferença entre as áreas estudadas (Quadro 5), com os valores variando de 3,87 (PL2N6) a 17,04 (CAP) $\mathrm{mg} \mathrm{kg}^{-1} \mathrm{~h}^{-1}$ de glicose (base seca). Kumari e Singaram (1995) observaram que a atividade da celulase relaciona-se com a fertilidade do solo e que maiores produções de biomassa microbiana correlacionaram-se com aumento na atividade enzimática, indicando que o aumento da atividade dessa enzima possivelmente seja em razão do aumento na mineralização de nutrientes pelos microrganismos do solo. A falta de significância entre os tratamentos se deve à desuniformidade na incorporação de resíduos vegetais ao solo, resíduos esses que contêm celulose, substrato da enzima.

As análises multivariadas foram processadas com os valores das características relativas à respiração basal, ao $\mathrm{CBM}$ e ao $q \mathrm{CO}_{2}$, pois apresentaram estruturas semelhantes (Figura 1). 
Quadro 5. Atividade das enzimas fosfatase ácida e alcalina, arilsulfatase e celulase em amostras de solo de áreas degradadas por mineração de cassiterita na Floresta Nacional do Jamari, RO, submetidas a processos de recuperação, e de áreas de mata nativa e de capoeira

\begin{tabular}{|c|c|c|c|c|}
\hline Tratamento & Fosfatase ácida & Fosfatase alcalina & Arilsulfatase & Celulase \\
\hline & \multicolumn{3}{|c|}{$\mathrm{mg} \mathrm{kg}^{-1} \mathrm{SS} \mathrm{h}^{-1}$ de $p$-nitrofenol } & $\mathrm{mg} \mathrm{kg}^{-1} \mathrm{SS} \mathrm{h}^{-1}$ glicose \\
\hline PL1N4 & $60,34 \mathrm{a}$ & $7,37 \mathrm{a}$ & $12,64 \mathrm{~b}$ & $10,34 \mathrm{a}$ \\
\hline PL2N6 & $37,51 \mathrm{a}$ & $5,54 \mathrm{a}$ & $5,07 \mathrm{~b}$ & $3,87 \mathrm{a}$ \\
\hline PL3N5 & $37,91 \mathrm{a}$ & $5,03 \mathrm{a}$ & $6,78 \mathrm{~b}$ & $8,56 \mathrm{a}$ \\
\hline RS4N5 & $44,48 \mathrm{a}$ & $11,29 \mathrm{a}$ & $6,87 \mathrm{~b}$ & $11,13 \mathrm{a}$ \\
\hline RS5N5 & $60,60 \mathrm{a}$ & $4,85 \mathrm{a}$ & $5,85 \mathrm{~b}$ & $8,78 \mathrm{a}$ \\
\hline RC6N5/6 & $35,57 \mathrm{a}$ & $6,26 \mathrm{a}$ & $3,09 \mathrm{~b}$ & $5,36 \mathrm{a}$ \\
\hline PL7N6 & $73,39 \mathrm{a}$ & $8,62 \mathrm{a}$ & $10,63 \mathrm{~b}$ & $11,46 \mathrm{a}$ \\
\hline PL8N6 & $51,12 \mathrm{a}$ & $8,43 \mathrm{a}$ & $4,96 \mathrm{~b}$ & $11,27 \mathrm{a}$ \\
\hline RU9N4 & $51,81 \mathrm{a}$ & $6,11 \mathrm{a}$ & $8,36 \mathrm{~b}$ & $6,91 \mathrm{a}$ \\
\hline PL10N6 & $33,68 \mathrm{a}$ & $11,64 \mathrm{a}$ & $25,55 \mathrm{a}$ & 9,95 a \\
\hline Mata & $44,33 \mathrm{a}$ & $8,23 \mathrm{a}$ & $37,86 \mathrm{a}$ & $11,29 \mathrm{a}$ \\
\hline Capoeira & $69,83 \mathrm{a}$ & $14,29 \mathrm{a}$ & $37,13 \mathrm{a}$ & $17,04 \mathrm{a}$ \\
\hline
\end{tabular}

Médias seguidas pela mesma letra na mesma coluna não diferem entre si pelo Teste Scott-Knott a $5 \%$.

Observou-se a formação de dois grupos distintos: G1, constituído pelos tratamentos PL2N6, RS5N5 e RU9N4; e G2, pelos tratamentos MATA, CAP, PL1N4, PL3N5, RS4N5, RC6N5/6, PL7N6, PL8N6 e PL10N6.

A estrutura complexa formada pelos dois primeiros componentes principais CP1 e CP2 (Figura 2) e a correlação das variáveis com os componentes principais (Quadro 6) permitiram, em complemento, a caracterização das variáveis que mais discriminaram na formação dos grupos G1 e G2.

O componente CP1 concentrou 85,22\% da variabilidade original (Figura 2). Os atributos biológicos considerados apresentaram dependência com as amostras contidas no grupo G2, que evidenciaram os maiores teores desses atributos (Quadro 7). Isso indica que essas áreas apresentaram maiores valores para esses atributos. O componente CP2 concentrou 13,13\% da variabilidade original.

Os tratamentos PL1N4, PL3N5, RS4N5, RC6N5/6, PL7N6, PL8N6 e PL10N6 estavam em estádio de recuperação mais avançado que os PL2N6, RU9N4 e RS5N5.

Análises multivariadas foram processadas com os valores das características relativas à respiração basal, $\mathrm{CBM}$ e ao $q \mathrm{CO}_{2}$, pois apresentaram estruturas semelhantes (Figura 2). Observou-se a formação de dois grupos distintos: G1, constituído pelos tratamentos PL2N6, RS5N5 e RU9N4; e G2, pelos tratamentos MATA, CAP, PL1N4, PL3N5, RS4N5, RC6N5/6, PL7N6, PL8N6 e PL10N6.

Quanto aos atributos químicos do solo, as análises multivariadas foram processadas com os valores das características relativas aos teores de

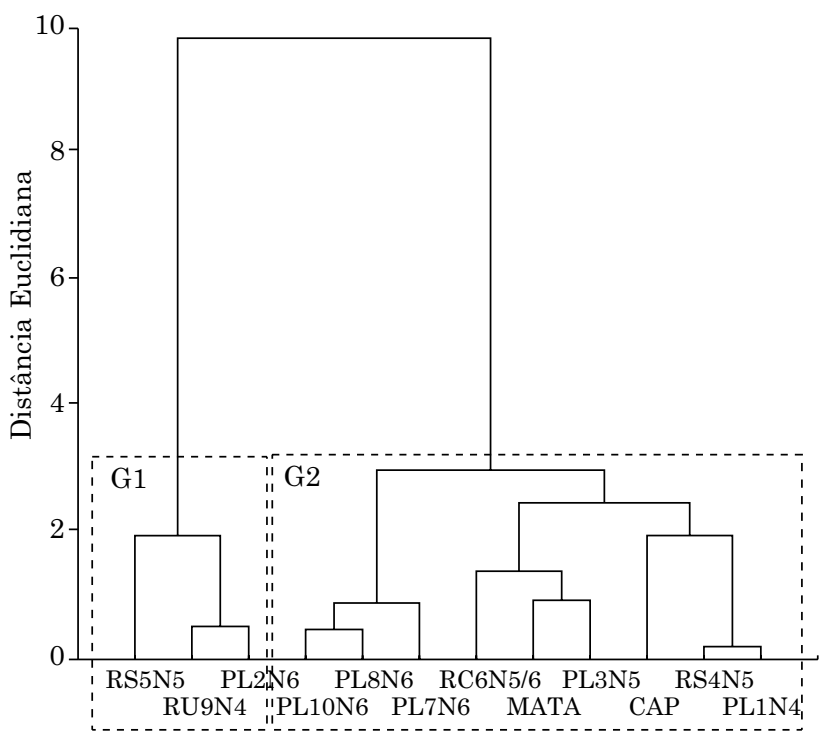

Figura 1. Dendrograma resultante da análise de agrupamento das diferentes áreas, utilizando a distância euclidiana como coeficiente de similaridade e o algoritmo Ward como método de agrupamento quanto aos atributos bioquímicos e biológicos.

Quadro 6. Correlação entre respiração basal, carbono da biomassa microbiana (CBM), quociente metabólico e dois componentes principais da análise multivariada

\begin{tabular}{lcc}
\hline Variável & CP1 (85,22\%) & CP2 (13,13 \%) \\
\hline Respiração basal & $\mathbf{- 0 , 9 8 2 7}$ & $-0,0609$ \\
CBM & $\mathbf{- 0 , 9 1 0 4}$ & $-0,3967$ \\
Quociente metabólico & $\mathbf{0 , 8 7 2 7}$ & $-0,4824$ \\
\hline
\end{tabular}




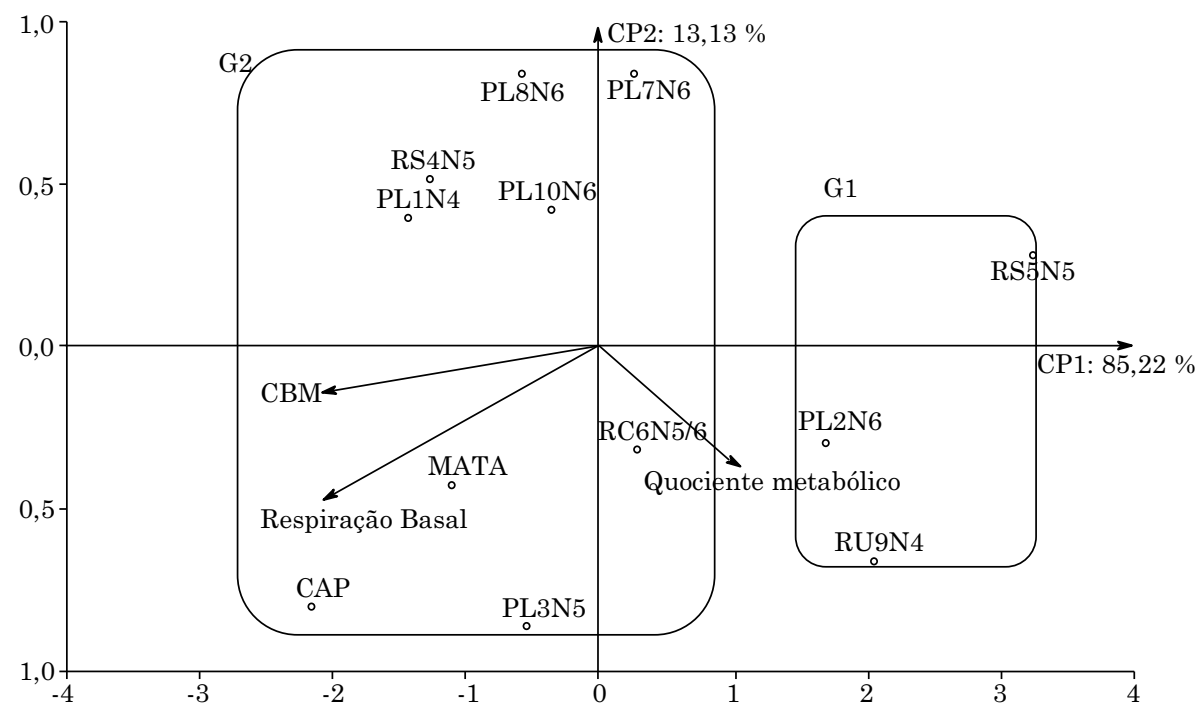

Figura 2. Gráfico biplot construído com os dois primeiros componentes principais, evidenciando a distribuição dos atributos bioquímicos e biológicos avaliados nas áreas.

Quadro 7. Correlação entre os atributos químicos do solo e dois componentes principais da análise multivariada

\begin{tabular}{lcc}
\hline Variável & CP $\mathbf{~}$ & CP 2 \\
\hline $\mathrm{P}\left(\mathrm{mg} \mathrm{dm}^{-3}\right)$ & $\mathbf{- 0 , 7 4 3 5}$ & $-0,4530$ \\
$\mathrm{MO}\left(\mathrm{g} \mathrm{dm}^{-3}\right)$ & $\mathbf{- 0 , 7 4 0 4}$ & $-0,6368$ \\
$\mathrm{pH}\left(\mathrm{CaCl}_{2}\right)$ & $\mathbf{0 , 9 5 1 9}$ & $-0,1635$ \\
$\mathrm{~K}^{+}\left(\mathrm{mmol}_{\mathrm{c}} \mathrm{dm}^{-3}\right)$ & $-0,5127$ & $\mathbf{- 0 , 5 3 8 9}$ \\
$\mathrm{Ca}^{2+}\left(\mathrm{mmol}_{\mathrm{c}} \mathrm{dm}^{-3}\right)$ & $\mathbf{0 , 8 3 0 7}$ & $\mathbf{- 0 , 5 2 4 3}$ \\
$\mathrm{Mg}^{2+}\left(\mathrm{mmol}_{\mathrm{c}} \mathrm{dm}^{-3}\right)$ & $\mathbf{0 , 8 0 8 7}$ & $\mathbf{- 0 , 5 4 1 4}$ \\
$\mathrm{H}+\mathrm{Al}\left(\mathrm{mmol}_{\mathrm{c}} \mathrm{dm}^{-3}\right)$ & $\mathbf{- 0 , 9 1 3 7}$ & $-0,3223$ \\
$\mathrm{SB}\left(\mathrm{mmol}_{\mathrm{c}} \mathrm{dm}^{-3}\right)$ & $\mathbf{0 , 8 2 4 5}$ & $\mathbf{- 0 , 5 5 5 3}$ \\
$\mathrm{CTC}\left(\mathrm{mmol}_{\mathrm{c}} \mathrm{dm}^{-3}\right)$ & $\mathbf{- 0 , 8 6 0 3}$ & $-0,4303$ \\
$\mathrm{~V}(\%)$ & $\mathbf{0 , 9 4 8 5}$ & $-0,2765$ \\
\hline
\end{tabular}

MO: matéria orgânica; $\mathrm{H}+\mathrm{Al}$ : acidez potencial; $\mathrm{SB}$ : soma de bases; CTC: capacidade de troca catiônica; e V: saturação por bases.

$\mathrm{P}, \mathrm{K}^{+}, \mathrm{Ca}^{2+}, \mathrm{Mg}^{2+}$, matéria orgânica (MO), acidez potencial $(\mathrm{H}+\mathrm{Al})$, capacidade de troca catiônica (CTC), soma de bases (SB) e saturação por bases (V). Observou-se a formação de dois grupos distintos: G1, constituído pelo tratamento MATA; e G2, pelos tratamentos CAP, PL1N4, PL2N6, PL3N5, RS4N5, RS5N5, RC6N5/6, PL7N6, PL8N6, RU9N4 e PL10N6 (Figura 3).

O componente CP1 concentrou 67,69 \% da variabilidade original (Figura 4). Os atributos químicos teor de $\mathrm{P}(\mathrm{r}=-0,74), \mathrm{K}^{+}(\mathrm{r}=-0,51), \mathrm{H}+\mathrm{Al}$ $(\mathrm{r}=-0,91)$, matéria orgânica $(\mathrm{r}=-0,74)$ e CTC $(r=-0,86)$ indicaram dependência com as amostras contidas no grupo G1 (MATA), que apresentaram os maiores teores desses atributos, pois se situam à

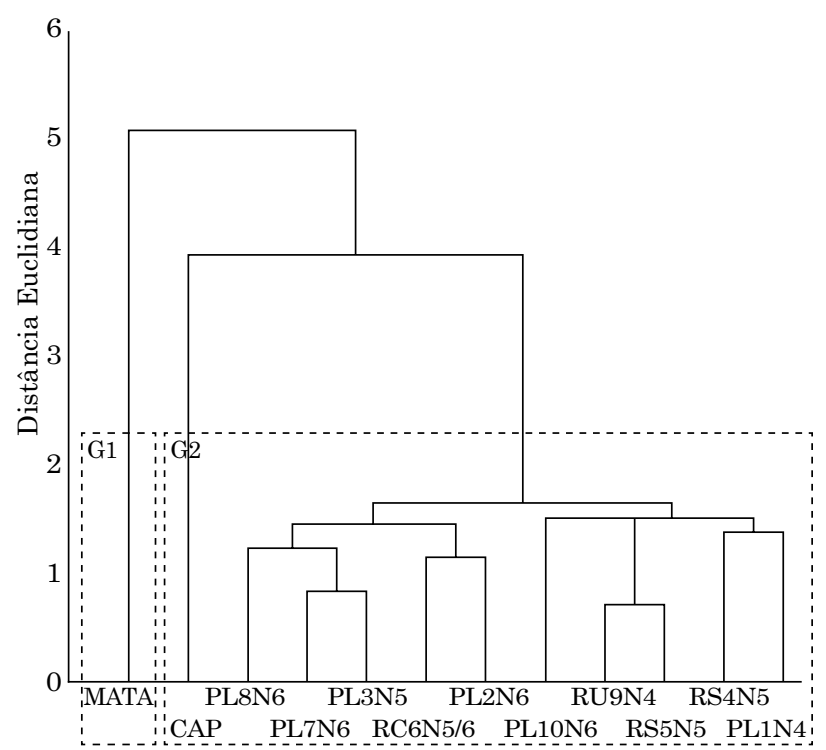

Figura 3. Dendrograma resultante da análise de agrupamento das diferentes áreas, utilizando a distância euclidiana como coeficiente de similaridade e o algoritmo Single Linkage como método de agrupamento quanto aos atributos químicos.

esquerda de CP1 (Quadro 8, Figura 4). O componente CP2 concentrou $21,70 \%$ da variabilidade original. $\mathrm{O} \mathrm{pH}(\mathrm{r}=0,95), \mathrm{V}(\mathrm{r}=0,94), \mathrm{SB}(\mathrm{r}=0,82), \mathrm{Ca}$ $(\mathrm{r}=0,83)$ e $\mathrm{Mg}(\mathrm{r}=0,80)$ caracterizaram as áreas do grupo G2, pois se situaram à direita de CP1 e apresentaram sinal positivo. Isso indicou que essas áreas mais próximas apresentaram maiores teores desses atributos. 


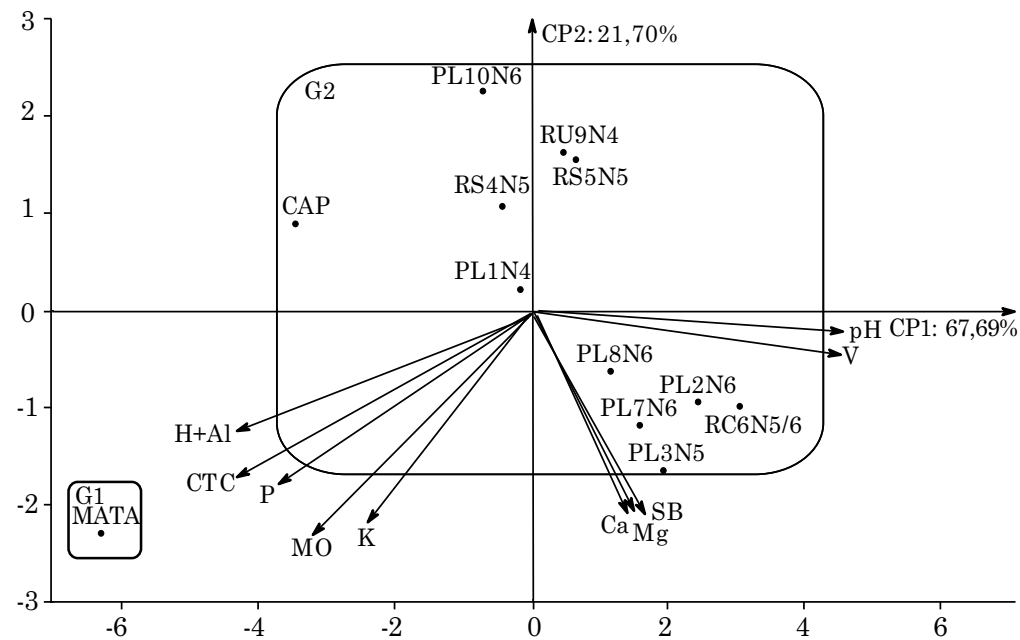

Figura 4. Gráfico biplot construído com os dois primeiros componentes principais, evidenciando a distribuição dos atributos químicos avaliados nas áreas.

Observou-se que áreas em recuperação se assemelharam ao tratamento CAP, que é uma área no entorno das minas, onde já foi feito algum tipo de ação (casas, estradas, pátios), mas que não foram mineradas e onde não ocorreu qualquer intervenção, apresentando vegetação relativamente diferente da MATA.

\section{CONCLUSÕES}

As análises dos atributos químicos, bioquímicos e biológicos do solo apresentaram respostas diferenciadas nos níveis de recuperação das áreas degradadas em recuperação e em áreas de mata e capoeira.

As áreas 1 (PL1N4), 4 (RS4N5), 6 (RC6N5/6), 7 (PL7N6), 8 (PL8N6) e 10 (PL10N6) estavam em estádio avançado de recuperação ao compará-las com solos de mata e de capoeira por meio das análises multivariadas quanto às características de respiração basal, carbono da biomassa microbiana e quociente metabólico no solo.

Os atributos químicos de fertilidade do solo evidenciam que todas as áreas mineradas em processo de recuperação já se aproximam da capoeira, evidenciando que o programa de recuperação adotado vem obtendo êxito.

Os atributos bioquímicos carbono da biomassa microbiana do solo e respiração basal e os químicos $\mathrm{H}+\mathrm{Al}$, capacidade de troca catiônica, P-resina e matéria orgânica foram os que mais estavam relacionados com a mata nativa.

\section{AGRADECIMENTOS}

Ao CNPq, pela bolsa de mestrado concedida ao primeiro autor e pela bolsa de pesquisador concedida ao terceiro autor. À Brascan Projetos de Recuperação Ambiental Ltda, pelo apoio financeiro e operacional.

\section{REFERÊNCIAS}

Alef K, Nannipieri P. Methods in applied soil microbiology and biochemistry. London: Academic Press; 1995.

Anderson TH, Domsch KH. Application of eco-physiological quotients $\left(\mathrm{qCO}_{2}\right.$ and $\left.\mathrm{qD}\right)$ on microbial biomasses from soils of different croppings histories. Soil Biol Biochem. 1990;22:251-5.

Anderson TH, Domsch KH. The metabolic quotient for $\mathrm{CO}_{2}$ $\left(\mathrm{qCO}_{2}\right)$ as a specific activity parameter to assess the effects of environmental conditions, such as $\mathrm{pH}$, on the microbial biomass of forest soils. Soil Biol Biochem. 1993;25:393-5.

Barreta D, Santos JCP, Figueiredo SR, Klauberg-Filho O. Efeito do monocultivo de pinus e da queima do campo nativo em atributos biológicos do solo no planalto sul catarinense. R Bras Ci Solo. 2005;29:715-24.

Cardoso EJBN, Freitas SS. A rizosfera. In: Cardoso EJBN, Tsai SM, Neves MCP, editores. Microbiologia dos solos. Campinas: Sociedade Brasileira de Ciência do Solo; 1992. p.41-58.

Carneiro MAC, Siqueira JO, Moreira FMS, Soares LL. Carbono orgânico, nitrogênio total, biomassa e atividade microbiana do solo em duas cronossequências de reabilitação após a mineração de bauxita. R Bras Ci Solo. 2008;12:621-32.

Carvalho F. Atributos bioquímicos como indicadores de qualidade do solo em florestas de Araucaria angustifolia (Bert.) O.Ktze. no estado de São Paulo [dissertação]. Piracicaba: Escola Superior de Agricultura Luiz de Queiroz; 2005. 
D’Andréa AF, Silva MLN, Curi N, Siqueira JO, Carneiro MAC. Atributos biológicos indicadores da qualidade do solo em sistemas de manejo na região do cerrado no sul do estado de Goiás. R Bras Ci Solo. 2002;26:913-23.

Dick RP, Breakwell DP, Turco RF. Soil enzyme activities and biodiversity measurements as integrative microbiological indicators. In: Doran JW, Jones AJ, editors. Methods for assessing soil quality. Madison: Soil Science Society of America; 1996. p.247-72.

Dick RP. Soil enzyme activities as integrative indicators of soil health. In: Pankhhurst BM, Doube BM, Gupta VVSR, editors. Biological indicators of soil health. Wallingford: $\mathrm{CAB}$ International; 1997. v.6. p.121-56.

Doran JW, Parkin TB. Defining and assessing soil quality. In: Doran JW, Coleman DC, Bezdicek DF, Etewart BA, editors. Defining soil quality for a sustainable environment. Madison: Soil Science Society of America; 1994. p.3-21.

Eivazi F, Tabatabai MA. Phosphatases in soils. Soil Biol Biochem. 1977;9:167-72.

Empresa Brasileira de Pesquisa Agropecuária - Embrapa. Centro Nacional de Pesquisa de Solos. Sistema brasileiro de classificação de solos. Brasília: Embrapa Produção de Informação; 1999.

Forster JC. Soil sampling, handling, storage and analysis - soil nitrogen. In: Alef K, Nannipieri P, editors. Methods in applied soil microbiology and biochemistry. London: Academic Press; 1995. p.74-87.

Garcia TC, Hernandez T, Costa F. Potential use of dehydrogenase activity as index of microbial activity in degraded soils. Commun Soil Sci Plant Anal. 1997;28:123-34.

Hair JF, Anderson RE, Tatham RL, Black W. Análise multivariada de dados. $5^{\text {a }}$.ed. Porto Alegre: Bookman; 2005.

Instituto Brasileiro do Meio Ambiente e dos Recursos Naturais Renováveis - Ibama. Plano de Manejo da Floresta Nacional do Jamari, RO. Brasília: 2005.

Instituto Brasileiro do Meio Ambiente e dos Recursos Naturais Renováveis - Ibama. Manual de recuperação de áreas degradadas pela mineração: Técnicas de revegetação. Brasília: 1990.

Kumari KK, Singaram P. Relationship among soil chemical, biochemical properties and enzyme activities. Madras Agric J. 1995;82:69-70.

Longo RM. Modificações em parâmetros físicos e químicos de Latossolos argilosos decorrentes da substituição da floresta amazônica e do cerrado por pastagens [tese]. Campinas: FEAGRI/Unicamp; 1999.

Longo RM, Ribeiro AI, Melo WJ. Caracterização física e química de áreas mineradas pela extração de cassiterita. Bragantia. 2005;64:101-7.

Lorenz SE, Mcgrath SP, Giller KE. Assessment of free-living nitrogen fixation activity as a biological indicator of heavy metal toxicity in soil. Soil Biol Biochem. 1992;24:601-6.

Margulis S. Causas do desmatamento da Amazônia Brasileira. (Banco Mundial - Trabalho em andamento para discussão pública) Brasília: Estação Gráfica; 2003.

Melo WJ, Melo GMP, Araujo ASF, Melo VP. Avaliação da atividade enzimática em amostras de solo. In: Figueiredo MBV, Burity HA, Oliveira JP, Santos CERS, Stanford NP, editores. Biotecnologia aplicada à agricultura: Textos de apoio e protocolos experimentais. Brasília/Recife: Embrapa Informação Tecnológica/ Instituto Agronômico de Pernambuco; 2010. p.153-87.

Mendes Filho PF. Potencial de reabilitação do solo de uma área degradada, através da revegetação e do manejo microbiano [tese]. Piracicaba: Escola Superior de Agricultura Luiz de Queiroz; 2004.

Moreira FMS, Siqueira JO. Microbiologia e bioquímica do solo. Lavras: Universidade Federal de Lavras, 2002.

Pancholy SK, Rice EL. Soil enzymes in relation to old field succession: Amylase, cellulase, invertase, dehydrogenase, and urease. Soil Sci Soc Am J. 1973;37:47-50.

Peña MLP, Marques R, Jahnel MC, Anjos A. Respiração microbiana como indicador de qualidade de solo em ecossistema florestal. Floresta. 2005;35:117-27.

Raij Bvan, Cantarella H, Quaggio JA, Furlani AMC, editores. Recomendações de adubação e calagem para o Estado de São Paulo. $2^{\text {a }}$.ed. Campinas: Instituto Agronômico de Campinas/ Fundação IAC; 1997. (Boletim técnico, 100).

Raij Bvan, Andrade JC, Cantarella H, Quaggio JA. Análise química para avaliação da fertilidade de solos tropicais. Campinas: Instituto Agronômico de Campinas; 2001.

Ribeiro BF. Mineração: Efeitos no meio ambiente e saúde humana. Campinas: Universidade de Campinas; 2000. p.325-39.

Sánchez MLE. Recuperação de áreas degradadas na mineração. São Paulo: EPUSP; 2000.

Schinner F, Öhlinger R, Kandeler E, Margesin R. Enzymes involved in intracellular metabolism. Methods in soil biology. Berlim: Springer-Verlag; 1996. p.235-43.

Schuner J, Rosswall T. Fluorescein diacetate hydrolysis as a measure of total microbial activity in soil and litter. Appl Environ Microbiol. 1982;43:1256-61.

Smyth TJ. Manejo da fertilidade do solo para introdução sustentada de cultivos na Amazônia. In: Alvarez V VH, Fontes LEF, Fontes MPF, editores. O solo nos grandes domínios morfoclimáticos do Brasil e o desenvolvimento sustentado. Viçosa, MG: Sociedade Brasileira de Ciência do Solo; 1996. p.71-93.

Srisvastava SC, Singh JS. Microbial C, N and P in dry tropical forest soils: Effects of alternate land-user and nutrient flux. Soil Biol Biochem. 1991;23:117-24.

Tabatabai MA, Bremner JM. Arylsulfatase activity of soils. Soil Sci Soc Am J. 1970;34:225-9.

Tabatabai MA. Soil enzymes. In: Weaver RW, Angle JS, Bottomley PS, editors. Methods of soil analysis: microbiological and biochemical properties. Madison: Soil Science Society of America; 1994. p.775-883.

Teixeira TT. Aplicação de lodo de estação de tratamento de água em solo degradado por mineração de cassiterita [tese]. Jaboticabal: Universidade Estadual de São Paulo; 2004.

Vance ED, Brookes PC, Jenkinson DS. An extraction method for measuring soil microbial biomass C. Soil Biol Biochem. 1987;19:703-7.

Williamson JC, Johnson DB. Conservation of mineral nitrogen in restored soils at opencast coal mine sites: II - The effects of inhibition of nitrification and organic amendments on nitrogen losses and soil microbial biomass. Eur J Soil Sci. 1994;45:319-26. 